\title{
实验增温对陆地生态系统根系生物量的影响
}

\author{
魏春雪 1,2 杨 璐 ${ }^{2,3}$ 汪金松 $2^{*}$ 杨家明 1,2 史嘉炜 ${ }^{1,2}$ 田大栓 ${ }^{2}$ 周青平 $1^{*}$ \\ 牛书 $\overline{\text { 匆 }}^{2}$
}

${ }^{1}$ 西南民族大学青藏高原研究院, 成都 $610041 ;{ }^{2}$ 中国科学院地理科学与资源研究所生态系统网络观测与模拟重点实验室, 北京 $100101 ;{ }^{3}$ 北京林业大 学国家林业和草原局森林经营工程技术研究中心, 北京 100083

摘 要 根系是植物吸收土壤水分和养分的重要器官, 驱动着多个生态系统过程, 该研究揭示了实验增温对根系生物量的影 响及机制, 可为气候变暖背景下土壤碳动态和生态系统过程的变化提供理论依据。该研究从已发表的151篇国内外研究论文 中收集到611组数据, 通过整合分析(meta-analysis)方法研究了实验增温对根系生物量(根系总生物量、粗根生物量、细根生物 量、根冠比)的影响, 并探讨了增温幅度、增温年限、增温方式的影响, 以及根系生物量对增温的响应与本底环境条件(生态 系统类型、年平均气温、年降水量、干旱指数)的关系。结果表明: (1)模拟增温使细根生物量显著增加 $8.87 \%$, 而对根系总生 物量、粗根生物量、根冠比没有显著影响; (2)中等强度增温 $\left(1-2{ }^{\circ} \mathrm{C}\right)$ 使得细根生物量和根冠比分别提高 $14.57 \%$ 和 $23.63 \%$; 中 短期增温实验 $(<5$ 年)对细根生物量具有促进影响, 而长期增温实验 $(\geqslant 5$ 年)使细根生物量有降低的趋势; 开顶箱增温和红外辐 射增温分别使细根生物量显著提高了 $17.50 \%$ 和 $12.16 \%$, 而电缆加热增温使细根生物量和粗根生物量显著降低了 $23.44 \%$ 和 43.23\%; (3)不同生态系统类型对于增温响应不一致, 模拟增温使苔原生态系统细根生物量显著提高了 $21.03 \%$, 细根生物量对 增温的响应与本底年平均气温、年降水量、干旱指数均呈显著负相关关系。

关键词 模拟增温; 根系生物量; 细根生物量; 陆地生态系统; 整合分析

魏春雪, 杨璐, 汪金松, 杨家明, 史嘉炜, 田大栓, 周青平, 牛书丽 (2021). 实验增温对陆地生态系统根系生物量的影响. 植物生态学报, 45, 1203-1212. DOI: $10.17521 /$ cjpe.2021.0195

\section{Effects of experimental warming on root biomass in terrestrial ecosystems}

WEI Chun-Xue ${ }^{1,2}$, YANG Lu ${ }^{2,3}$, WANG Jin-Song ${ }^{2 *}$, YANG Jia-Ming ${ }^{1,2}$, SHI Jia-Wei ${ }^{1,2}$, TIAN Da-Shuan ${ }^{2}$, ZHOU Qing-Ping ${ }^{1 *}$, and NIU Shu-Li ${ }^{2}$

${ }^{1}$ Institute of Qinghai-Tibet Plateau, Southwest Minzu University, Chengdu 610041, China; ${ }^{2}$ Key Laboratory of Ecosystem Network Observation and Modeling, Institute of Geographic Sciences and Natural Resources Research, Chinese Academy of Sciences, Beijing 100101, China; and ${ }^{3}$ Research Center of Forest Management Engineering of State Forestry and Grassland Administration, Beijing Forestry University, Beijing 100083, China

\footnotetext{
Abstract

Aims Roots are an important organ for plants to absorb soil water and nutrients and can drive multiple ecosystem processes. This study disentangles the effects and underlying mechanisms of experimental warming on root biomass in terrestrial ecosystems, aiming to better understand soil carbon dynamics and inform the changes in ecosystem processes under climate warming.

Methods In this study we compiled data on 611 paired observations from 151 published peer-reviewed articles, and analyzed the responses of several plant root biomass variables, including total root biomass, fine root biomass, coarse root biomass, and root:shoot ratio, to warming using meta-analysis. The responses of root biomass to the magnitude, duration and method of warming treatments, and the warming responses of root biomass in relation to background environmental conditions (i.e. ecosystem types, mean annual air temperature, mean annual precipitation, and aridity index) were examined.

Important findings Simulated warming significantly increased fine root biomass by $8.87 \%$, but had no significant effects on total root biomass, coarse root biomass, and root:shoot ratio. Moderate magnitude of warming $\left(1-2{ }^{\circ} \mathrm{C}\right)$ significantly increased fine root biomass and root:shoot ratio by $14.57 \%$ and $23.63 \%$, respectively. While the short- to medium-term $(<5$ years) warming enhanced fine root biomass, a long-term warming $(\geqslant 5$

收稿日期Received: 2021-05-20 接受日期Accepted: 2021-09-15

基金项目：国家自然科学基金(31800404)和中央高校基本科研业务费(2020YYXS66)。Supported by the National Natural Science Foundation of China (31800404) and the Fundamental Research Funds for the Central Universities (2020YYXS66).

* 通信作者Corresponding authors (Wang JS, wangjinsong@igsnrr.ac.cn; Zhou QP, qpingzh@aliyun.com)
} 
years) had a tendency to decrease it. Both open-top chamber and infrared radiators significantly increased fine root biomass by $17.50 \%$ and $12.16 \%$, respectively; whilst heating cables significantly decreased fine root biomass by $23.44 \%$ and coarse root biomass by $43.23 \%$. The warming responses of root biomass were inconsistent across different ecosystem types. Notably, warming significantly increased fine root biomass by $21.03 \%$ in tundra ecosystems. The response of fine root biomass to simulated warming had significant and negative correlations with the background mean annual air temperature, mean annual precipitation, and aridity index.

Key words simulated warming; root biomass; fine root biomass; terrestrial ecosystems; meta-analysis

Wei CX, Yang L, Wang JS, Yang JM, Shi JW, Tian DS, Zhou QP, Niu SL (2021). Effects of experimental warming on root biomass in terrestrial ecosystems. Chinese Journal of Plant Ecology, 45, 1203-1212. DOI: 10.17521/cjpe.2021.0195

工业革命以来, 由于人类活动加剧导致大气中 温室气体浓度不断升高, 由此引发的全球变暖已经 成为不争的事实。根据IPCC评估报告预测到 21 世纪 末全球地表平均温度将上升 $0.3-4.8{ }^{\circ} \mathrm{C}$ (IPCC, 2013)。气候变暖直接影响陆地生态系统的结构和功 能, 进而改变生态系统碳循环的各个过程, 如光合 作用、土壤呼吸、调落物分解、细根动态、植物生 产力等(Kirschbaum, 2004; Loik et al., 2004; Majdi \& Öhrvik, 2004; 徐小锋等, 2007; Xu et al., 2010; 李晓 杰等, 2017)。此外, 由于温度变化引起的植物生长 节律、群落物种组成和结构、养分循环的改变亦会 间接影响上述碳循环过程(Niu et al., 2010; Yu et al., 2010), 进而对全球气候变化产生强烈的反馈作用。

根系是连接植物地上地下的重要器官, 根系通 过吸收土壤水分和养分满足植物生长(张小全和吴 可红, 2001), 并且能够储存碳水化合物, 且根系通 过不断的生长、死亡、周转和分解过程参与生态系 统的物质交换和能量流动, 驱动生态系统的碳氮循 环(卫星等, 2008; Yin et al., 2014)。根据Jackson等 (1997)对全球不同植被的估计, 仅小于 $2 \mathrm{~mm}$ 细根的 周转, 每年要消耗全球陆地生态系统净初级生产力 的 $30 \%$ 以上, 且细根通过周转每年向地下输入有机 物占总输入的 $50 \%$ 左右(Wan et al., 2004)。另外, 细 根分解后能够输送大量的有机质和养分进入土壤, 每年对土壤碳库的贡献率达 $25 \%-80 \%$ (Eldhuset et al., 2006; Sun et al., 2013)。资源在粗根和细根间的 分配权衡是植物重要的生存策略, 体现着植物对环 境变化的适应能力。粗根不仅对植物生长起支撑作 用, 而且也在碳存储中扮演重要角色, 并且粗根生 物量的增加有利于植物根系向深层分布以维持植物 的正常生长(间慧等, 2014)。同样, 根冠比是植物长 期适应自然选择的结果(毛晋花等, 2018), 在一定程 度上可反映植物在响应全球变化时采取的策略方 式。植物根系在调节陆地生态系统对气候变暖的响
应中起着重要作用, 因此, 研究根系对气候变暖的 响应, 对于理解陆地生态系统碳动态及其对气候变 化的反馈至关重要。

温度上升对根系的影响体现在多个方面。首先, 气候变暖直接影响植物光合速率, 改变植物物候, 延长植物的生长季(叶旺敏等, 2019), 进而影响根系 生物量; 其次, 温度能够影响土壤动物及微生物的 数量和活性、土壤有机质的分解速率以及养分可利 用性导致根系生物量发生改变(Bradford et al., 2016; Li et al., 2020); 再者, 温度升高会导致土壤水分含 量的降低(Gimbel et al., 2015), 使土壤水分成为根 系生长的限制因子, 植物为获取足够水分会增加根 系的长度或密度, 导致根系生物量以及植物根冠比 发生变化(Joslin et al., 2000; 尹华军等, 2008)。然而, 已有的研究表明根系生物量对温度升高的响应并不 一致, 不同生态系统根系生物量对增温响应表现为 增加(Hollister \& Flaherty, 2010)、不变(Volder et al., 2004; Tokida et al., 2011)或减少(Zhou et al., 2011; Coldren et al., 2016)。增温幅度、增温年限、增温方 式会对植物生长产生影响。例如, Usami等(2001)的 结果表明增温 $4.5{ }^{\circ} \mathrm{C}$ 使温带森林根系生物量增加了 25\%, Zhou等(2011)发现增温5 ${ }^{\circ} \mathrm{C}$ 使哈佛森林根系 生物量降低约 $40 \%$, 而Han等(2018)发现增温 $3{ }^{\circ} \mathrm{C}$ 对 温带森林根系生物量无影响。Wang等(2021)的整合 分析表明增温促进了细根生物量和生产力, 随着增 温幅度增加, 增温对细根生物量的影响减弱, 并且 细根生物量受到增温幅度和增温年限的共同作用。 另外, 本底环境也影响着增温效应, 增温对根系生 物量的促进作用在湿润的生态系统更明显(Wan et al., 2004), 而在干旱生态系统, 温度升高引起的 水分胁迫有可能会抑制根系生长(Bai et al., 2010)。 尽管如此, 增温如何影响根系生物量及其机制还存 在很大的不确定性。

本研究基于野外增温控制实验，采用整合分析

www.plant-ecology.com 
的方法，从151篇已发表的国内外论文中收集到611 组数据, 探究增温对根系生物量(总生物量、细根生 物量、粗根生物量、根冠比)的影响; 通过亚组分析揭 示根系生物量对增温幅度、增温年限、增温方式的 响应以及不同生态系统类型之间的差异; 阐明增温对 根系生物量的影响及机制, 为理解气候变暖背景下 土壤碳动态和生态系统过程的变化提供理论依据。

\section{1 材料和方法}

\section{1 文献选择与数据库建立}

数据来源于Web of Science、Google Scholar、 CNKI等中英文期刊数据库, 搜索的关键词包括: climate change、 experimental warming、 warming、 temperature、 biomass、 root biomass、 underground、 belowground、fine root biomass、fine root。共收集 到151篇已发表的国内外文献，包括了611个配对的 观测值(对照和增温处理)用于整合分析。所选用的 文献须符合以下标准: (1)所选研究必须设有对照组 和处理组, 均为野外田间实验; (2)对于同一研究, 实验开始前其对照组和处理组均属于同一生态系统 且具有相同的气候、土壤条件; (3)对于多年实验收 集全部观测结果, 并将每一年结果作为独立变量, 同一年内多次测定的变量采用平均值进行计算; (4) 对于研究中包括模拟增温处理的多因素控制实验,
只选择对照组和模拟增温处理组数据; (5)所选研究 对照组和处理组的平均值、样本量、标准差或标准 误可以直接从文中获得或者从图表中提取。使用 GetData v2.22 (http://getdata-graph-digitizer.com)对 图中的数据进行提取。

收集的变量包括: 根系总生物量 $(T R B)$, 细根生 物量 $(F R B)$, 粗根生物量 $(C R B)$, 根冠比 $(R / S)$ 。其中 细根为直径小于 $2 \mathrm{~mm}$ 的根系。同时收集每项研究实 验地的经纬度、海拔、年降水量 $(M A P)$ 、年平均气 温 $(M A T)$ 、生态系统类型、增温幅度、增温年限以 及增温方式。根据数据结构将数据进行如下分组: 增温幅度 $\left(\leqslant 1{ }^{\circ} \mathrm{C} 、 1-2{ }^{\circ} \mathrm{C} 、 \geqslant 2{ }^{\circ} \mathrm{C}\right)$; 增温年限 $(\leqslant 2$ 年、 $2-5$ 年、 $\geqslant 5$ 年); 增温方式(开顶箱、红外辐射、 电缆加热、温室增温、反射), 生态系统类型(农田、 森林、草地、苔原、湿地)。所收集研究点的纬度跨 度从 $42.70^{\circ} \mathrm{S}$ 到 $78.17^{\circ} \mathrm{N}$, 年平均气温范围为 $-12-28$ ${ }^{\circ} \mathrm{C}$, 年降水量范围为114-2 $418 \mathrm{~mm}$ 。图1为本研究所 涉及研究点的分布情况。

\section{2 整合分析}

本文运用R 4.0.3 (https://www.r-project.org)中 lme4、ggplot2等程序包进行数据处理和作图, 采用 响应比 $(R R)$ 的自然对数 (ln $R R$ )作为效应值(Hedges \& Olkin, 1985)评估增温对根系生物量的影响。其计 算方法为:

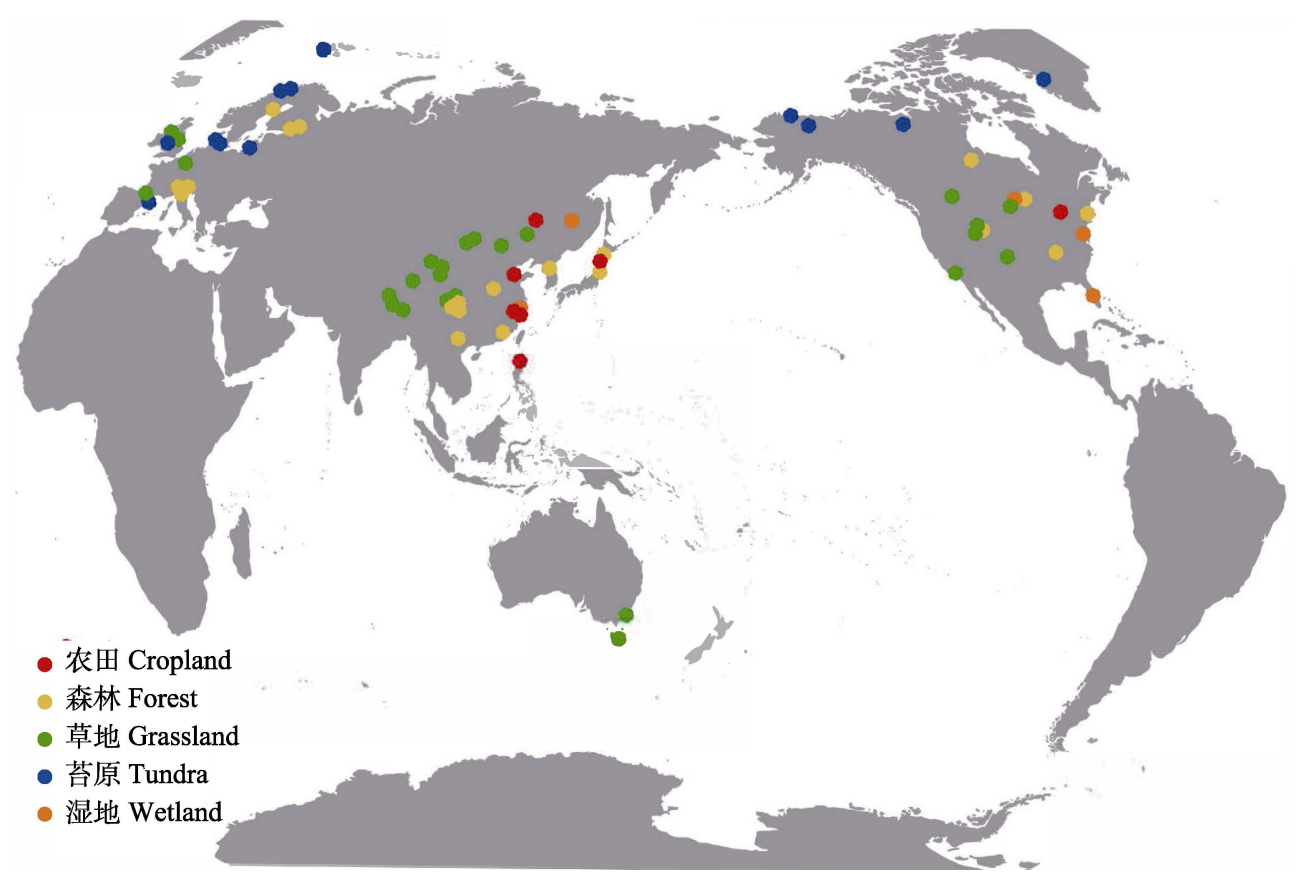

图1 整合分析中研究点的全球分布。

Fig. 1 Global distribution of study sites in the meta-analysis. 


$$
\ln R R=\ln \left(X_{\mathrm{t}} / X_{\mathrm{c}}\right)
$$
式中, $X_{\mathrm{t}} 、 X_{\mathrm{c}}$ 分别表示一个独立研究中处理组和对照 组的平均值。整合分析研究中, 单个研究的加权方 式对效应值的影响极大, 以往研究多采用样本方差 或者标准差进行加权, 但这会提高个别观测值的重 要性, 从而导致效应值受到很大影响。因此, 本研究 采用处理组和对照组的样本量进行加权 (Zhang et al., 2018):

$$
W_{\mathrm{rr}}=\left(N_{\mathrm{c}} \times N_{\mathrm{t}}\right) /\left(N_{\mathrm{c}}+N_{\mathrm{t}}\right)
$$

式中, $W_{\mathrm{rr}}$ 表示每一观测效应值的权重, $N_{\mathrm{c}} 、 N_{\mathrm{t}}$ 分别表 示对照组和处理组的样本量。对于每个观测值, 使 用以下模型(公式(3)) 检测 $\ln R R$ 是否与 0 重叠以及 $\ln$ $R R$ 是否受增温幅度、增温年限、增温方式及生态系 统类型等因素的影响, 并将不同研究多年实验的每 一年结果作为独立变量检验增温年限对根系生物量 的影响, 在混合效应模型中将每个研究作为随机变 量考虑其随机效应。

$$
\begin{aligned}
\ln R R= & \beta_{0}+\beta_{1} \times M+\beta_{2} \times D+\beta_{3} \times M E+\beta_{4} \\
& \times E+\pi_{\text {study }}+\varepsilon
\end{aligned}
$$

式中, $\beta$ 为系数, $\pi_{\text {study }}$ 为观测值的随机效应, $\varepsilon$ 是样本 误差, $M$ 为增温幅度, $D$ 为增温年限, $M E$ 为增温方式, $E$ 为生态系统类型。 $\beta_{0}$ 为总体效应值, $\beta_{1}$ 为增温幅度 的效应值, $\beta_{2}$ 为增温年限的效应值, $\beta_{3}$ 为增温方式的 效应值, $\beta_{4}$ 为生态系统类型的效应值, 其中干旱指 数(年降水量/年蒸发量) 通过CGIAR-CSI全球干旱数 据库获得(Zomer et al., 2008)。为了便于解释, 将 $\ln R R$ 及其对应的置信区间 $(\mathrm{CI})$ 转换为相应的百分 比变化。

$$
\mathrm{CI}=\left(\mathrm{e}^{\ln R R}-1\right) \times 100 \%
$$

\section{2 结果和分析}

\section{1 根系生物量对模拟增温的响应}

总体上，模拟增温促进植物根系生物量。与对 照相比, 增温使细根生物量显著增加 $8.87 \%$ (95\% CI: $1 \%-16 \%$, 图 2$)$, 而对根系总生物量 $(95 \%$ CI: $-6 \%-$ $16 \%)$, 粗根生物量 $(95 \%$ CI: $-20 \%-29 \%)$ 和根冠比 (95\% CI: $-8 \%-23 \%)$ 虽然有促进作用, 但影响均不 显著(图2)。

\section{2 根系生物量对增温幅度、增温年限、增温方式 的响应}

根系生物量对增温幅度的响应不一致。不同增 温幅度均提高根系总生物量和粗根生物量, 但影响

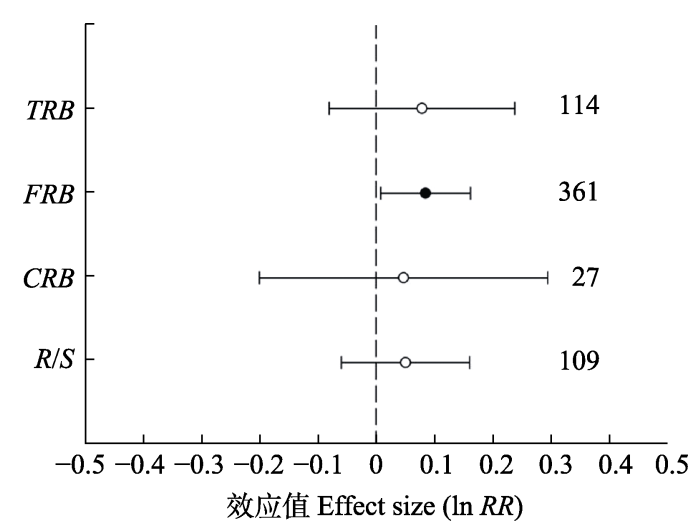

图2 模拟增温对根系总生物量 $(T R B)$ 、细根生物量 $(F R B)$ 、 粗根生物量 $(C R B)$ 、根冠比 $(R / S)$ 的影响。右侧数字代表样本 量, 误差线代表 $95 \%$ 置信区间。实心圆代表增温处理效应达 到显著水平 $(p<0.05)$, 空心圆代表增温处理效应未达到显 著水平。

Fig. 2 Effects of simulated warming (ln $R R$ ) on total root biomass (TRB), fine root biomass $(F R B)$, coarse root biomass $(C R B)$, and root:shoot ratio $(R / S)$. The values within the graphic panel show the sample sizes for each of the variables. Error bars represent $95 \%$ confidence intervals. Solid circle represent significant warming effects $(p<0.05)$, and hollow circles indicate insignificant warming effects.

均不显著 $(p>0.05)$ 。而中等强度 $\left(1-2{ }^{\circ} \mathrm{C}\right)$ 增温使细 根生物量显著提高了 $14.57 \%$ (95\% CI: $1 \%-27 \%$, 图 $3 \mathrm{~B})$, 相反, 高强度 $\left(\geqslant 2{ }^{\circ} \mathrm{C}\right)$ 增温则对细根生物量有 抑制作用 $(p>0.05)$ 。中等强度增温使根冠比显著提高 $23.63 \%$ (95\% CI: $2 \%-41 \%$ ，图3D), 而高强度增温则 降低了根冠比 $(p>0.05)$ 。

根系生物量对增温持续时间的响应也不一致， 其中短期增温和中期增温能够提高根系总生物量和 粗根生物量, 相反, 长期增温对二者起抑制作用, 但影响均不显著。相比短期和中期增温提高根系生 物量, 长期增温使细根生物量有降低趋势 $(p>0.05)$ 。

电缆加热使细根生物量和粗根生物量分别显著 降低了 $23.44 \%$ (95\% CI: $-47 \%--6 \%$, 图3B)和 $43.23 \%$ (95\% CI: $-104 \%--9 \%$, 图3C), 其余增温方式(开顶 箱增温、红外辐射增温、温室增温或反射)均增加了 根系总生物量、细根生物量以及粗根生物量, 其中, 开顶箱增温和红外辐射增温使得细根生物量分别显 著提高了 $17.50 \%$ (95\% CI: $2 \%-30 \%)$ 和 $12.16 \%$ (95\% CI: $1 \%-23 \%)(p<0.05)$ 。不同增温方式对根冠比均无 显著影响 $(p>0.05)$ 。

\section{3 根系生物量对模拟增温的响应与环境因子的 关系}

增温对根系总生物量、粗根生物量、根冠比的 影响在不同生态系统之间没有显著差异(图3A、3C、 
$3 \mathrm{D}, p>0.05)$, 增温使得苔原生态系统细根生物量 显著增加了 $21.03 \%$ (95\% CI: 2\%-30\%, 图3B), 而对 其他生态系统细根生物量没有显著影响 $(p>0.05)$ 。 由表 1 和图 4 可知, 细根生物量对增温的响应与年平
均气温、年降水量、干旱指数均呈显著负相关关系 $(p<0.01$, 图4), 而根系总生物量、粗根生物量和根 冠比对增温的响应与气候因子无显著关系 $(p>$ $0.05)$ 。
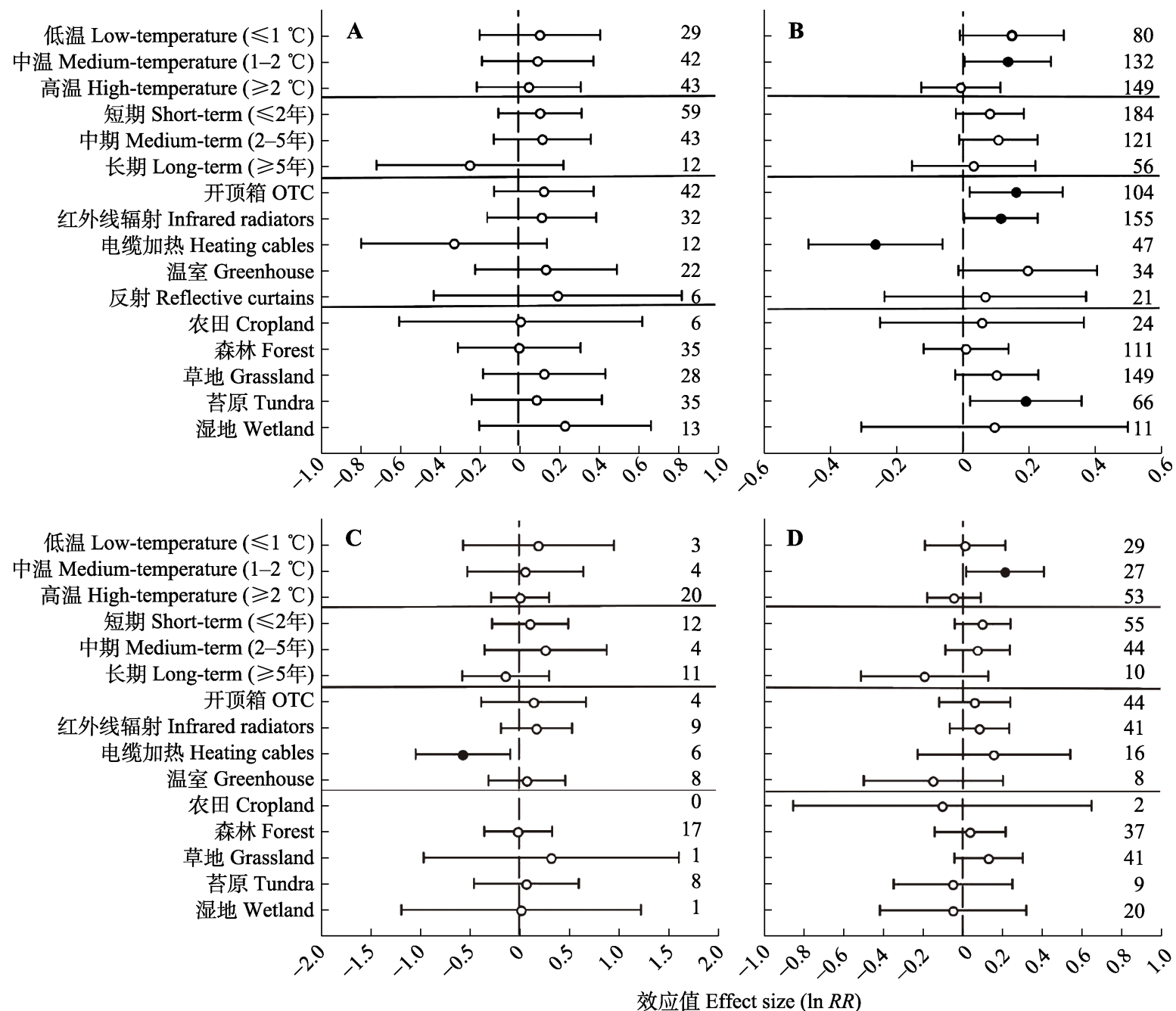

图3 模拟增温对根系总生物量 $(\mathbf{A}) 、$ 细根生物量 $(\mathbf{B}) 、$ 粗根生物量 $(\mathbf{C}) 、$ 根冠比 $(\mathbf{D})$ 的影响与增温幅度、增温年限、增温方式、 生态系统类型的关系。右侧数字代表样本量, 误差线代表 $95 \%$ 置信区间。实心圆代表增温处理效应达到显著水平 $(p<0.05)$, 空 心圆代表增温处理效应未达到显著水平。

Fig. 3 Effects of simulated warming ( $\ln R R)$ on total root biomass (A), fine root biomass (B), coarse root biomass (C) and root:shoot ratio (D) in relation to the magnitude, duration and method of warming and ecosystem types. The values within the graphic panels show the sample sizes for each of the variables. Error bars represent $95 \%$ confidence intervals. Solid circles represent significant warming effects $(p<0.05)$, and hollow circles indicate insignificant warming effects. OTC, open top container.

表1 模拟增温对根系总生物量 $(T R B)$ 、细根生物量 $(F R B)$ 、粗根生物量 $(C R B)$ 、根冠比 $(R / S)$ 的影响 $(\ln R R)$ 与年平均气温 $(M A T)$ 、年降水量 $(M A P)$ 、干旱 指数 $(A I)$ 的关系

Table 1 Effects of simulated warming on total root biomass $(T R B)$, fine root biomass $(F R B)$, coarse root biomass $(C R B)$ and root:shoot ratio $(R / S)$ in relation to mean annual air temperature $(M A T)$, mean annual precipitation $(M A P)$ and aridity index $(A I)$

\begin{tabular}{|c|c|c|c|c|c|c|c|c|c|}
\hline \multirow{2}{*}{$\begin{array}{l}\text { 根系生物量效应值 } \\
\text { Effect size of root biomass }\end{array}$} & \multicolumn{3}{|c|}{$M A T$} & \multicolumn{3}{|c|}{$M A P$} & \multicolumn{3}{|c|}{$A I$} \\
\hline & $d f$ & $F$ & $p$ & $d f$ & $F$ & $p$ & $d f$ & $F$ & $p$ \\
\hline$\overline{T R B}$ & 113 & 0.2352 & 0.603 & 113 & 1.1107 & 0.187 & 113 & 2.5974 & 0.110 \\
\hline$F R B$ & 360 & 34.7600 & $0.000^{* * *}$ & 360 & 43.6520 & $0.000^{* * *}$ & 360 & 16.7260 & $0.000^{* * *}$ \\
\hline$C R B$ & 26 & 0.0826 & 0.776 & 26 & 1.4002 & 0.248 & 26 & 3.4489 & 0.075 \\
\hline$R / S$ & 108 & 2.7660 & 0.099 & 108 & 0.1030 & 0.749 & 108 & 0.1094 & 0.742 \\
\hline
\end{tabular}

$* * *, p<0.001$. 

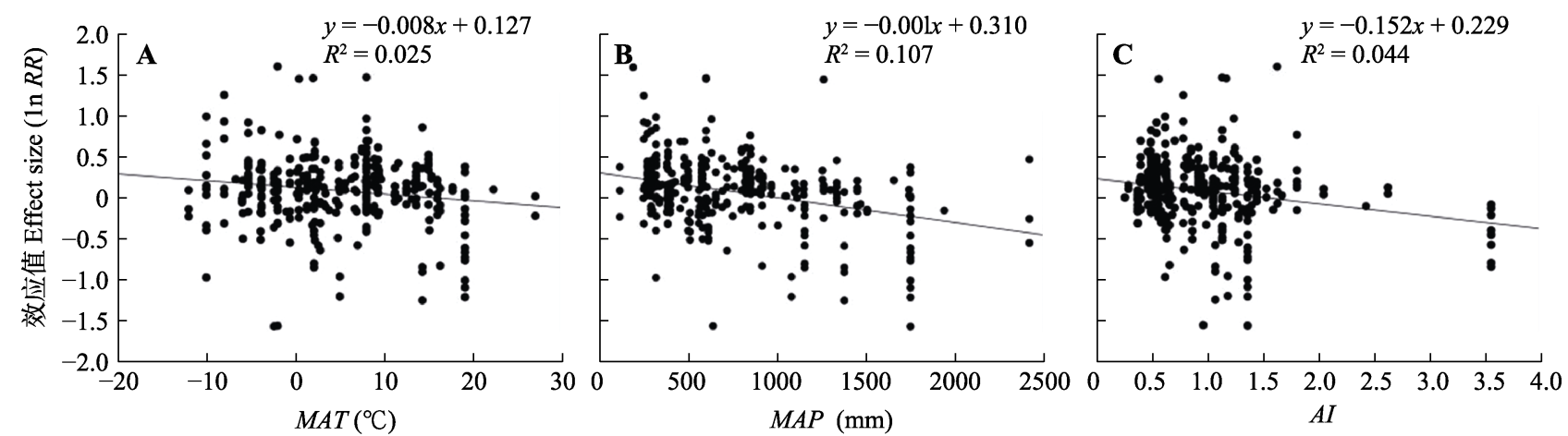

图4 增温对细根生物量的影响 $(\ln R R)$ 与年平均气温 $(M A T)(\mathbf{A})$ 、年降水量 $(M A P)(\mathbf{B})$ 、干旱指数 $(A I)(\mathbf{C})$ 的关系。

Fig. 4 Effect of simulated warming $(\ln R R)$ on fine-root biomass in relation to mean annual air temperature $(M A T)(\mathbf{A})$, mean annual precipitation $(M A P)(\mathbf{B})$, and aridity index $(A I)(\mathbf{C})$.

\section{3 讨论}

\section{1 模拟增温对根系生物量的影响}

本研究结果表明, 模拟增温对陆地生态系统根 系生物量具有促进作用, 且主要体现在细根生物量, 这与Wang等(2021)整合分析的结果一致。增温显著 增加了陆地生态系统细根生物量, 表明细根对气候 变暖敏感性更高。增温对细根的促进作用主要有以 下几个方面的原因。首先, 增温能够延长植物的生 长季(Zhao et al., 2017), 对植物根系产生直接影响; 其次, 相比粗根, 细根对环境的变化更敏感 (Leppälammi-Kujansuu et al., 2013), Wan等(2004)和 Bai等(2010)研究结果均表明细根生物量会随土壤 温度升高而增加, 而模拟增温能够提高土壤温度; 再者, 实验增温会导致植物蒸发量增加引起土壤水 分的降低(Chen et al., 2016), 细根是植物吸收水分 的主要器官, 因此会增加细根生物量来缓解水分限 制; 此外, 土壤氮有效性也是影响细根生物量的重 要原因, 已有研究表明模拟增温能够使土壤氮矿化 速率提高 $46 \%$, 土壤氮含量增加能够提高细根生物 量(Rustad et al., 2001; Lee et al., 2007)。

环境因子的改变会影响植物生物量的分配模式 (Domisch et al., 2002), 本研究结果表明增温未改变 植物地上、地下分配, 这可能是植物本身通过地上 和地下生长协同变化共同抵御外界温度的升高, 增 温促进植物地上部分生长, 因此需要更多水分、养 分维持植物地上生长, 从而导致植物地下生物量增 加, 故而未改变植物根冠比。

3.2 增温幅度、增温年限、增温方式对根系生物量 的影响

Rustad等(2001)和Lin等(2010)的整合分析表明,
陆地植物生物量对不同幅度增温的响应没有差异。 但本研究发现中等强度 $\left(1-2{ }^{\circ} \mathrm{C}\right)$ 增温显著增加细根 生物量, 与高强度增温相比, 中等强度增温对土壤 温度和土壤水分的影响较小。Li等(2011)在青藏高 原高寒草甸的模拟增温结果表明, 当增温幅度为 $5.16{ }^{\circ} \mathrm{C}$ 时土壤水分减少了 $7.7 \%$, 而当增温幅度为 $2.59{ }^{\circ} \mathrm{C}$ 时土壤水分只减少 $1.8 \%$, 在西藏高山生态 系统的研究发现, 土壤温度升高 $1.52{ }^{\circ} \mathrm{C}$ 不会显著影 响土壤水分, 而土壤温度升高 $1.98{ }^{\circ} \mathrm{C}$ 则使得土壤水 分显著降低了 $16.1 \%$ (Zhong et al., 2016)。由此可知, 较高的增温幅度导致土壤水分大幅度降低可能会加 重水分胁迫, 抑制细根的生长。本研究发现不同增 温年限对根系生物量的影响均不显著, 与中短期增 温相反, 长期增温对细根生物量产生一定的抑制作 用, 这可能是由于长期增温后导致植物群落结构发 生改变, 将会导致根系深度或根系碳分配发生变化 (Liu et al., 2018), 进而影响细根生物量。

由于增温装置在设计、技术和增温原理上的差 别, 可能会导致植物对模拟增温的响应并不相同 (牛书丽等, 2007)。目前, 采用的增温装置主要分为 主动增温和被动增温两类, 土壤加热管道、电缆加 热和红外线辐射器属于主动增温装置, 而开顶式生 长箱、温室和反射属于被动增温装置(甘琦杰等, 2021)。本研究发现开顶式生长箱和红外线辐射器两 种增温装置能够显著提高细根生物量。开顶箱增温 原理如同温室效应, 降低了风速, 减弱了空气流动 强度, 使得生长箱内热量不容易散失, 形成较为稳 定的增温环境, 温度升高通常会导致开顶式生长箱 内水分蒸发增强, 导致生长箱内空气湿度降低, 利 于植物根系生长(杨兵等, 2010; 朱彪和陈迎, 2020)。 红外辐射技术利用红外线的电磁辐射热传递, 以辐 
射方式传递热量而达到增温的目的, 红外辐射装置 可以使整个系统增温(侯彦会等, 2013), 从而使土壤 温度升高, 提高根系呼吸速率, 促进根系生长。本研 究发现电缆加热导致细根生物量和粗根生物量显著 降低, 原因在于电缆加热直接作用于土壤, 地表蒸 散作用加剧, 引起土壤湿度的降低比其他增温方式 更为显著，而根系生长易受到水分胁迫，导致生物 量降低。同时本研究发现电缆加热对细根生物量影 响程度大于粗根生物量, 可能是因为粗根起到运输 根的作用, 其木质化程度较高, 对土壤温度和水分 变化的响应不如细根明显。

\section{3 根系生物量对模拟增温的响应与本底环境条} 件的关系

本研究发现增温显著提高苔原生态系统细根生 物量, 这与Zamin等(2014)在北极苔原地区的研究 结果一致。首先, 高纬度地区生态系统中的植物主 要受低温限制, 因此比低纬度地区的植物更容易受 到温度的影响(Parmesan, 2007), 增温缓解了苔原地 区植物的低温限制, 提高了土壤微生物的活性, 加 快根系周转, 从而对根系生长起促进作用。Lin等 (2010)的整合分析也表明高纬度苔原生态系统比低 纬度的草原和森林生态系统受气候变暖的影响更 大。其次, 在苔原生态系统中通过模拟增温提高了 环境温度, 较高的温度会延长植物的生长期, 从而 提高植物的生产力, 增加植物地下分配, 导致细根 生物量增加。

本研究发现细根生物量对模拟增温的响应随着 年平均气温、年降水量和干旱指数增加而逐渐降低。 这表明寒冷地区, 如北极苔原生态系统, 易受到低 温限制, 而增温可以延长植物的生长季, 促进地下 生物量的增加(Zamin et al., 2014)。Malhotra等(2020) 在SPRUCE泥炭地进行的模拟增温实验结果表明, 增温引起植物细根生物量显著提高与土壤干旱有关, 由于水分或养分的限制, 相比地上部分, 植物增加 了地下细根的投资。相反, 在热带地区, 如热带雨林 水热条件较好, 环境温度较高, 模拟增温对该地区 植物根系产生的效应较小。

增温对细根生物量的促进作用在干旱地区更明 显, 干旱地区通常年降水量和干旱指数较小, 土壤 水分是影响植物生长的主要限制因素, 对干旱地区 增温后易造成土壤干旱, 植物为获得足够水分及养 分会增加对地下部分的投资，提高根系生物量; 而
在湿润地区，模拟增温引起的水分变化可能并没有 产生水分胁迫，因此对细根生长的影响较小。Song 等(2019)的研究结果表明增温提高干旱地区的根冠 比, 说明在干旱地区增温能够提高植物对根系的投 资, 而在湿润地区增温则提高了植物对地上茎的 投资。

\section{4 结论}

(1)模拟增温显著提高了细根生物量, 并且细根 生物量对增温的响应受本底环境的影响。增温对细 根的促进作用在寒冷、干旱的地区更明显。

(2)增温对根系生物量的影响受增温幅度、增温 年限、增温方式的影响。中等强度增温 $\left(1-2{ }^{\circ} \mathrm{C}\right)$ 显 著增加细根生物量, 中短期 $(<5$ 年)增温实验促进根 系生物量, 而长期 $(\geqslant 5$ 年)实验使得根系生物量有降 低趋势。

(3)电缆加热引起的土壤干旱程度高于开顶箱 和红外辐射增温这两种增温方式, 从而导致根系生 物量降低, 表明在评估增温对根系的影响时需考虑 不同增温装置的差异。

\section{参考文献}

Bai WM, Wan SQ, Niu SL, Liu WX, Chen QS, Wang QB, Zhang WH, Han XG, Li LH (2010). Increased temperature and precipitation interact to affect root production, mortality, and turnover in a temperate steppe: implications for ecosystem C cycling. Global Change Biology, 16, 13061316.

Bradford MA, Berg B, Maynard DS, Wieder WR, Wood SA (2016). Understanding the dominant controls on litter decomposition. Journal of Ecology, 104, 229-238.

Chen J, Luo YQ, Xia JY, Shi Z, Jiang LF, Niu SL, Zhou XH, Cao JJ (2016). Differential responses of ecosystem respiration components to experimental warming in a meadow grassland on the Tibetan Plateau. Agricultural and Forest Meteorology, 220, 21-29.

Coldren GA, Barreto CR, Wykoff DD, Morrissey EM, Langley JA, Feller IC, Chapman SK (2016). Chronic warming stimulates growth of marsh grasses more than mangroves in a coastal wetland ecotone. Ecology, 97, 3167-3175.

Domisch T, Finér L, Lehto T (2002). Growth, carbohydrate and nutrient allocation of Scots pine seedlings after exposure to simulated low soil temperature in spring. Plant and Soil, 246, 75-86.

Eldhuset TD, Lange H, de Wit HA (2006). Fine root biomass, necromass and chemistry during seven years of elevated aluminium concentrations in the soil solution of a 
middle-aged Picea abies stand. Science of Total Environment, 369, 344-356.

Gan QJ, Liu JL, Chen H (2021). Progress in research on field warming methods. Chinese Journal of Applied and Environmental Biology, 27, 1092-1101. [甘琦杰, 刘建亮, 陈 槐 (2021). 野外增温方法研究进展. 应用与环境生物学 报, 27, 1092-1101.]

Gimbel KF, Felsmann K, Baudis M, Puhlmann H, Gessler A, Bruelheide H, Kayler Z, Ellerbrock RH, Ulrich A, Welk E, Weiler M (2015). Drought in forest understory ecosystems-A novel rainfall reduction experiment. Biogeosciences, 12, 961-975.

Han SH, Kim S, Li G, Chang H, Yun SJ, An J, Son YH (2018). Effects of warming and precipitation manipulation on fine root dynamics of Pinus densiflora Sieb. et Zucc. seedlings. Forests, 9, 14. DOI: 10.3390/f9010014.

Hedges LV, Olkin I (1985). Statistical Methods for Metaanalysis. Academic Press, New York.

Hollister RD, Flaherty KJ (2010). Above- and below-ground plant biomass response to experimental warming in northern Alaska. Applied Vegetation Science, 13, 378-387.

Hou YH, Zhou GS, Xu ZZ (2013). An overview of research progress on responses of grassland ecosystems to global warming based on infrared heating experiments. Chinese Journal of Plant Ecology, 37, 1153-1167. [侯彦会, 周广 胜, 许振柱 (2013). 基于红外增温的草地生态系统响应 全球变暖的研究进展. 植物生态学报, 37, 1153-1167.]

IPCC (2013). Climate change: the physical science basis//IPCC. Contribution of Working Group I to the Fifth Assessment Report of the Intergovernmental Panel on Climate Change. Cambridge University Press, Cambridge, UK.

Jackson RB, Mooney HA, Schulze ED (1997). A global budget for fine root biomass, surface area, and nutrient contents. Proceedings of the National Academy of Sciences of the United States of America, 94, 7362-7366.

Joslin JD, Wolfe MH, Hanson PJ (2000). Effects of altered water regimes on forest root systems. New Phytologist, 147, 117-129.

Kirschbaum MUF (2004). Soil respiration under prolonged soil warming: Are rate reductions caused by acclimation or substrate loss? Global Change Biology, 10, 1870-1877.

Lee EH, Tingey DT, Beedlow PA, Johnson MG, Burdick CA (2007). Relating fine root biomass to soil and climate conditions in the Pacific Northwest. Forest Ecology and Management, 242, 195-208.

Leppälammi-Kujansuu J, Ostonen I, Strömgren M, Nilsson LO, Kleja DB, Sah SP, Helmisaari HS (2013). Effects of longterm temperature and nutrient manipulation on Norway spruce fine roots and mycelia production. Plant and Soil, 366, 287-303.

Li F, Peng YF, Chen LY, Yang GB, Abbott BW, Zhang DY, Fang K, Wang GQ, Wang J, Yu JC, Liu L, Zhang QW,
Chen KL, Mohammat A, Yang YH (2020). Warming alters surface soil organic matter composition despite unchanged carbon stocks in a Tibetan permafrost ecosystem. Functional Ecology, 34, 911-922.

Li N, Wang GX, Yang Y, Gao YH, Liu GS (2011). Plant production, and carbon and nitrogen source pools, are strongly intensified by experimental warming in alpine ecosystems in the Qinghai-Tibet Plateau. Soil Biology \& Biochemistry, 43, 942-953.

Li XJ, Liu XF, Lin CF, Chen SD, Xiong DC, Lin WS, Xu C, Xie JS, Yang YS (2017). Effects of experimental soil warming on plant biomass allocation during the early stages of succession in a subtropical forest in China. Acta Ecologica Sinica, 37, 25-34. [李晓杰, 刘小飞, 林成芳, 陈仕东, 熊德成, 林伟盛, 胥超, 谢锦升, 杨玉盛 (2017). 土壤增温调节中亚热带森林更新初期植物生物 量分配格局. 生态学报, 37, 25-34.]

Lin DL, Xia JY, Wan SQ (2010). Climate warming and biomass accumulation of terrestrial plants: a meta-analysis. New Phytologist, 188, 187-198.

Liu H, Mi Z, Lin L, Wang Y, Zhang Z, Zhang F, Wang H, Liu L, Zhu B, Cao G, Zhao X, Sanders NJ, Classen AT, Reich PB, He JS (2018). Shifting plant species composition in response to climate change stabilizes grassland primary production. Proceedings of the National Academy of Sciences of the United States of America, 115, 4051-4056.

Loik ME, Still CJ, Huxman TE, Harte J (2004). In situ photosynthetic freezing tolerance for plants exposed to a global warming manipulation in the Rocky Mountains, Colorado, USA. New Phytologist, 162, 331-341.

Majdi H, Öhrvik J (2004). Interactive effects of soil warming and fertilization on root production, mortality, and longevity in a Norway spruce stand in Northern Sweden. Global Change Biology, 10, 182-188.

Malhotra A, Brice DJ, Childs J, Graham JD, Hobbie EA, van der Stel H, Feron SC, Hanson PJ, Iversen CM (2020). Peatland warming strongly increases fine-root growth, Proceedings of the National Academy of Sciences of the United States of America, 117, 17627-17634.

Mao JH, Xing YJ, Yan GY, Wang QG (2018). A meta-analysis of the response of terrestrial plant biomass allocation to simulated N deposition. Acta Ecologica Sinica, 38, 3183-3194. [毛晋花, 邢亚娟, 间国永, 王庆贵 (2018). 陆生植物生物量分配对模拟氮沉降响应的Meta分析. 生态学报, 38, 3183-3194.]

Niu SL, Han XG, Ma KP, Wan SQ (2007). Field facilities in global warming and terrestrial ecosystem research. Journal of Plant Ecology (Chinese Version), 31, 262-271. [牛书丽, 韩兴国, 马克平, 万师强 (2007). 全球变暖与陆地生态 系统研究中的野外增温装置. 植物生态学报, 31 , 262-271.]

Niu SL, Sherry RA, Zhou XH, Wan SQ, Luo YQ (2010).

www.plant-ecology.com 
Nitrogen regulation of the climate-carbon feedback: evidence from a long-term global change experiment. Ecology, 91, 3261-3273.

Parmesan C (2007). Influences of species, latitudes and methodologies on estimates of phenological response to global warming. Global Change Biology, 13, 1860-1872.

Rustad L, Campbell J, Marion G, Norby R, Mitchell M, Hartley A, Cornelissen J, Gurevitch J, GCTE-NEWS (2001). A meta-analysis of the response of soil respiration, net nitrogen mineralization, and aboveground plant growth to experimental ecosystem warming. Oecologia, 126, 543-562.

Song J, Wan SQ, Piao SL, Knapp AK, Classen AT, Vicca S, Ciais P, Hovenden MJ, Leuzinger S, Beier C, Kardol P, Xia JY, Liu Q, Ru JY, Zhou ZX, et al. (2019). A meta-analysis of 1,119 manipulative experiments on terrestrial carbon-cycling responses to global change. Nature Ecology \& Evolution, 3, 1309-1320.

Sun T, Mao ZJ, Han YY (2013). Slow decomposition of very fine roots and some factors controlling the process: a 4-year experiment in four temperate tree species. Plant and Soil, 372, 445-458.

Tokida T, Adachi M, Cheng WG, Nakajima Y, Fumoto T, Matsushima M, Nakamura H, Okada M, Sameshima R, Hasegawa $\mathrm{T}$ (2011). Methane and soil $\mathrm{CO}_{2}$ production from current-season photosynthates in a rice paddy exposed to elevated $\mathrm{CO}_{2}$ concentration and soil temperature. Global Change Biology, 17, 3327-3337.

Usami T, Lee J, Oikawa T (2001). Interactive effects of increased temperature and $\mathrm{CO}_{2}$ on the growth of Quercus myrsinaefolia saplings. Plant, Cell \& Environment, 24, 1007-1019.

Volder A, Edwards EJ, Evans JR, Robertson BC, Schortemeyer M, Gifford RM (2004). Does greater night-time, rather than constant warming alter growth of managed pasture under ambient and elevated atmospheric $\mathrm{CO}_{2}$ ? New Phytologist, 162, 397-411.

Wan SQ, Norby RJ, Pregitzer KS, Ledford J, O’Neill EG (2004). $\mathrm{CO}_{2}$ enrichment and warming of the atmosphere enhance both productivity and mortality of maple tree fine roots. New Phytologist, 162, 437-446.

Wang J, Defrenne C, McCormack ML, Yang L, Tian D, Luo Y, Hou E, Yan T, Li Z, Bu W, Chen Y, Niu S (2021). Fineroot functional trait responses to experimental warming: a global meta-analysis. New Phytologist, 230, 1856- 1867.

Wei X, Liu Y, Chen HB (2008). Anatomical and functional heterogeneity among different root orders of Phellodendron amurense. Journal of Plant Ecology (Chinese Version), 32, 1238-1247. [卫星, 刘颖, 陈海波 (2008). 黄波 罗不同根序的解剖结构及其功能异质性. 植物生态学 报, 32, 1238-1247.]

Xu GP, Hu YG, Wang SP, Zhang ZH, Chang XF, Duan JC, Luo CY, Chao ZG, Su AL, Lin QY, Li YN, Du MY
(2010). Effects of litter quality and climate change along an elevation gradient on litter mass loss in an alpine meadow ecosystem on the Tibetan Plateau. Plant Ecology, 209, 257-268.

Xu XF, Tian HQ, Wan SQ (2007). Climate warming impacts on carbon cycling in terrestrial ecosystems. Journal of Plant Ecology (Chinese Version), 31, 175-188. [徐小锋, 田汉勤, 万师强 (2007). 气候变暖对陆地生态系统碳循 环的影响. 植物生态学报, 31, 175-188.]

Yan H, Dong XL, Zhang SR (2014). Coarse root biomass distribution characteristics in a Chinese subtropical evergreen broadleaved forest. Chinese Science Bulletin, 59, 24162425. [阊慧, 董心亮, 张守仁 (2014). 古田山亚热带常 绿阔叶林粗根生物量分布特征. 科学通报, 59, 24162425.]

Yang B, Wang JC, Zhang YB (2010). Effect of long-term warming on growth and biomass allocation of Abies faxoniana seedlings. Acta Ecologica Sinica, 30, 5994-6000. [杨兵, 王进闯, 张远涁 (2010). 长期模拟增温对岷江 冷杉幼苗生长与生物量分配的影响. 生态学报, 30 , 5994-6000.]

Ye WM, Xiong DC, Yang ZJ, Zhu YG, Zhang QF, Liu XF, Lin WS, Xu C, Zhang J, Yang YS (2019). Effect of soil warming on growth and photosynthetic characteristics of Cunninghamia lanceolata saplings. Acta Ecologica Sinica, 39, 2501-2509. [叶旺敏, 熊德成, 杨智杰, 朱益广, 张秋 芳，刘小飞，林伟盛，胥超，张景，杨玉盛 (2019). 模拟 增温对杉木幼树生长和光合特性的影响. 生态学报, 39 , 2501-2509.]

Yin CY, Pu XZ, Xiao QY, Zhao CZ, Liu Q (2014). Effects of night warming on spruce root around non-growing season vary with branch order and month. Plant and Soil, 380, 249-263.

Yin HJ, Lai T, Cheng XY, Jiang XM, Liu Q (2008). Warming effects on growth and physiology of seedlings of Betula albo-sinensis and Abies faxoniana under two contrasting light conditions in subalpine coniferous forest of western Sichuan, China. Journal of Plant Ecology (Chinese Version), 32，1072-1083. [尹华军, 赖挺, 程新颖, 蒋先敏, 刘庆 (2008). 增温对川西亚高山针叶林内不同光环境 下红桦和岷江冷杉幼苗生长和生理的影响. 植物生态 学报, 32, 1072-1083.]

Yu H, Luedeling E, Xu J (2010). Winter and spring warming result in delayed spring phenology on the Tibetan Plateau. Proceedings of the National Academy of Sciences of the United States of America, 107, 22151-22156.

Zamin TJ, Bret-Harte MS, Grogan P (2014). Evergreen shrubs dominate responses to experimental summer warming and fertilization in Canadian mesic low arctic tundra. Journal of Ecology, 102, 749-766.

Zhang TA, Chen HYH, Ruan HH (2018). Global negative effects of nitrogen deposition on soil microbes. The ISME 
Journal, 12, 1817-1825.

Zhang XQ, Wu KH (2001). Fine-root production and turnover for forest ecosystems. Scientia Silvae Sinicae, 37(3), 126-138. [张小全, 吴可红 (2001). 森林细根生产和周 转研究. 林业科学, 37(3), 126-138.]

Zhao JX, Li RC, Li X, Tian LH (2017). Environmental controls on soil respiration in alpine meadow along a large altitudinal gradient on the central Tibetan Plateau. Catena, 159, 84-92.

Zhong ZM, Shen ZX, Fu G (2016). Response of soil respiration to experimental warming in a highland barley of the Tibet. SpringerPlus, 5, 137. DOI: 10.1186/s40064-016-1761-0.

Zhou YM, Tang JW, Melillo JM, Butler S, Mohan JE (2011). Root standing crop and chemistry after six years of soil warming in a temperate forest. Tree Physiology, 31, 707-717.

Zhu B, Chen Y (2020). Techniques and methods for field warming manipulation experiments in terrestrial ecosystems. Chinese Journal of Plant Ecology, 44, 330-339. [朱 彪, 陈迎 (2020). 陆地生态系统野外增温控制实验的技 术与方法. 植物生态学报, 44, 330-339.]

Zomer RJ, Trabucco A, Bossio DA, Verchot LV (2008). Climate change mitigation: a spatial analysis of global land suitability for clean development mechanism afforestation and reforestation. Agriculture, Ecosystem and Environment, 126, 67-80.

责任编委: 白 娥 编辑: 赵 航 